\title{
12 Increasing regional competitiveness in exports through smart specialisations: the case of Spanish and Polish regions
}

The problem of competitiveness has been broadly discussed in the literature. All participants of the debate agree that competitiveness as a category is not precise, which leaves it open to various interpretations. The existing literature identifies new characteristics of competitiveness. This is probably the reason why there is no single definition of the concept.

Given the abundance of different theoretical and empirical approaches to competitiveness and recent deliberations on the smart specialisation strategy towards its application in regional strategic documents, the chapter depicts how the smart specialisation concept can be used in order to raise regional competitiveness. By analysing different regional strategies of Polish and Spanish regions and relating them to real trade flows, we not only depict the importance of smart specialisation exports thereof but also formulate important policy implications regarding the inclusion of foreign trade activity in regional strategic documents.

\subsection{Defining competitiveness}

The first theorist to tackle the problem of competitiveness comprehensively at the country level was Porter. He believed that competitive advantage is rooted in "the results achieved by firms in competitive markets." If their advantage is a lasting one, it becomes a sustainable competitive advantage. At its source are lower costs, diversification and concentration on specific products or markets (Porter, 2010).

It should be noted that according to Porter (1998), competitive advantage results from a connection between the unique environment of a country and its competitive benefits, created by various industries (firms). Ultimately, it is the effectiveness of enterprises that is behind the economic strengths of countries or regions. The fact is stressed by Huggins et al. (2013), who say that in identifying the premises for national competitiveness, Porter pointed to the role of firms, their strength and "capacity to innovate". Competitiveness changes with time and does not depend only on the strengths and strategies of the firm, but also on how the rivals behave. "Competitiveness is not driven by static efficiency, but competitiveness is a function of dynamic progressiveness, innovation and an ability to change and improve” (Porter, 2010).

The concept of competitiveness is not, in Porter's view, unequivocal. The category of productivity is more precise. A high standard of living is now definitely less 
dependent on the abundance of factors of production, low cost of capital and labour or low currency prices than on productivity and the ability to improve it. It is also stressed by Krugman (1990, p. 9), who resolutely argues that "Productivity isn't everything, but in the long run it is almost everything”, while Begg (1999, p. 795) maintains that productivity and competitiveness are identical concepts "at the full employment level of national income".

OECD (1992) defines competitiveness as "the degree, to which a state may produce goods and services that should pass the test of international competition and in the same time to maintain and develop its incomes at the national level, in the condition of market liberalisation".

In the Sixth Periodic Report of the European Commission (1999), competition is defined as "the ability to produce goods and services which meet the test of international markets, while at the same time maintaining high and sustainable levels of income or, more generally, the ability of (regions) to generate, while being exposed to external competition, relatively high income and employment levels," and "in other words, for a region to be competitive, it is important to ensure both quality and quantity of jobs".

Ciampi (1995, pp. 2-3) highlights the fact that competitiveness can be verified by the development of international specialisation. "Competitiveness implies elements of productivity, efficiency, profitability. But it is not an end in itself or a target. It is a powerful means to achieve rising standards of living and increasing social welfare - a tool for achieving targets. Globally, by increasing productivity and efficiency in the context of international specialisation, competitiveness provides the basis for raising people's earnings in a noninflationary way. It increases the value-added and growth potential, stimulating not only resource-saving innovation but the investment to expand capacity and to create jobs as well”.

In many of the studies devoted to the issue of competitiveness, three levels of analysis may be identified; the first one deals with countries, the second with regions and the third one with firms. It should be noted that the competitiveness of firms, unlike that of nations or regions, is mercilessly verified by the market - the enterprises unable to stand the pressure of competition are eliminated from the market. ${ }^{31}$

By contrast, regions are perceived as deadlocked in space, and their existence continues irrespective of the condition and strength of their economies. Another important difference is that regional competition is not a zero-sum game; a rise in the competitiveness of one region does not occur at the expense of reducing the output of its rival or eliminating it altogether - as is often the case with firms.

Although factors affecting the sustainability or increased market share are different in the case of firms, regions and nations, many characteristics of competitiveness

31 With the possible exception of state-owned companies, which may be assisted through various forms of public aid. 
are the same at all levels of analysis. While studying the competitiveness of firms or regions, it is impossible to ignore the macroeconomic conditions of the country or the quality of its institutions. Furthermore, as it has already been mentioned, the competitiveness of regions or nations is rooted in the power of the firms operating in their territory. This is because "competitive advantage is created and sustained through a highly localized process” (Porter, 1990, p. 19). For this reason, the levels of analysis tend to overlap, as competitiveness studies identify a host of hierarchically structured factors, which give a comprehensive description of competitiveness.

\subsection{Concepts related to competitiveness}

In the discussion of competitiveness, many other categories emerge, like competitive position, competitive capacity, competitive advantage. The concept of competitive advantage and competitiveness are equivalent to the perfect competition model. However, competition is now distorted by market prices, production factor prices, marketing costs and currency rates (Kannapiran and Fleming, 1999, p. 10).

Competitive position is determined by static advantages, which identify the scale of the differences (in absolute or relative terms) in the productivity of labour and capital. As the level of competitiveness and competitive advantages apply to different "competitiveness players", the advantages are not permanent and tend to fluctuate.

Bossak (2000, p. 47) defines competitive capacity as "the ability to fight, compete for the benefits connected with the nation's participation in the international division of labour". The ability to fight successfully occurs when the competitive position is sufficiently strong.

The ability is shaped during a process of constant change (so it is dynamic) and may result in improvement or deterioration of the competitive position. If less-developed regions manage to raise productivity vis-à-vis their competitors, the process of catching up occurs.

An improvement or a deterioration in the competitive position does not automatically cause changes in the competitive capacity. If a higher share in global export trade is used as a measure of the change in competitive capacity, it may not necessarily be an outcome of a better competitive position, as it may result from a better market for low-processed goods or materials, changes in terms of trade or exchange rate fluctuations.

A competitive position (and consequently, a competitive capacity) is sustainable in the long run if the pattern of exports matches the trends of global demand. It should be added, however, that these are high-tech goods that should prevail; otherwise, the advantages will not last long (e.g. a high share of oil in exports in a period of great global demand does not create such an advantage).

Hausner (2013) points out that absolute advantages are static, while the relative (comparative) advantages are dynamic. Once Ricardo's definition has been accepted, 
the authors claim, it means that "some of the resources in a given economy are used less effectively than in the economies with which it has to compete, but at the same time there are periods in which they are used more effectively, narrowing the absolute productivity gap between the resources. This means that the comparative advantages may lead to absolute advantages”.

The common element in all these definitions is that competitiveness or the related concepts must per se involve the need to be compared with others (other entities, regions or nations). Martin (2003, pp. 2-4) confirms that competitiveness must be based on the test of international markets. Such a test should contain two parts: (a) the ability to sell one's goods abroad and (b) to face strong competition from foreign competitors in an open economy.

For a region to improve its competitive position, it is necessary that the firms located there conduct high-value-added activities. "To be competitive...means to be able to employ national resources, notably the nation's workforce, in such a way as to earn a rising level of real income through specialisation and trade in the world economy" (Scott, 1985). This corroborates the previously mentioned claim by Porter that enterprises are the leverage of competitiveness, securing competitive advantages for a region. Budd and Hirmis (2004, p. 1018) reiterate that there are "two parts to achieve a competitive advantage. First, the ways in which firms organize and undertake distinct activities is the basis for the growth and competitive advantage. Second, the process of discovering novel and enhanced ways of competing in the market. This constitutes innovation that includes not only technical progress but also improved working and managerial methods”.

\subsection{The smart approach in regions' development path and}

\section{competitiveness}

A discussion of a policy to enhance the competitive potential must not ignore smart specialisation, which has recently become a very prominent concept, aiming at boosting regional innovativeness, as well as their competitiveness and eventually economic growth. Through this concept, the EU tries to decrease the productivity difference of its regions with global leaders (Foray, David, and Hall, 2009) by implementing a novel approach towards innovation policy, where development of regional competitive advantage at the international scale is a crucial aspect (Dziemianowicz and Peszat, 2014). The concept is based on the place-based and evidence-based approach to building regional policy (Tödtling and Trippl, 2005), abandoning the prior top-down attitude in favour of bottom-up policies, with significant input of non-governmental entities in the process of policy prioritisation (Gianelle, Kyriakou, Cohen, and Przeor, 2016). 
According to Foray (2014) smart specialisations refer to capacity an economic system has (i.e. region), in order to find/create new specialities through the discovery of new opportunity domains (activities), thanks to the existing concentration of competences, resources, capital in those domains. This capacity should have the proper strength to initiate structural transformations, diversification of economic activity, modernisation or emergence of new services/industries. Therefore, to some extent, it is usually adjacent to the existing regional strengths/advantages.

The rationale of smart specialisations relies on the effective use of locally available resources ${ }^{32} /$ structures, subsequently transformed with the support of new (but related) research activities (Hassink and Gong, 2019) that focus on finding R\&D and innovation in the existing economic structures across sectors (Foray, 2014). These new innovative domains may emerge as projects that are a complement to the existing economic structures/capabilities. Thus, the concept is more about "smart diversification" or "diversified specialisation" or "related variety" than on preserving the existing industry structures/sectoral composition of regional economies, with which it is commonly mistaken.

Within the concept, regions have to identify their key areas of competences, assets, potential or existing comparative advantages, thanks to which they may differ from other regions. These specialisations should rely on the innovative (in comparison to other regions) creation of capabilities (Asheim, 2019), which will eventually lead to incremental structural shifts, which opens more dynamic growth trajectories, even for regions whose advantages tend to fade. Actually, regional economic transformation is one of the key goals of the smart specialisation strategy, which with the use of "punctual and targeted government intervention supports the most promising new activities in terms of discovery, experimentation, potential spillover and structural changes" (Foray, 2014) tries to raise regions' competitiveness. Thus, it leads to new specialities developments, which are somehow related to the existing production assets.

In the policy, the attention is put to (Foray et al., 2009): (i) concentration of priorities, (ii) concentration on the transformation of structures (not structures itself), (iii) favouring the development discovery logic. This may be concisely summarized as the creation of such a development path for the region, in which growth factors are adequate to the endogenous potential (strengths, prospects and advantages are properly used), where a region can identify areas in which it will be able to generate innovations/comparative advantages (Trippl, Zukauskaite, and Healy, 2019). Thus, the approach means the rejection of the one-size-fits-all approach, in exchange for tailored-made policy, maximising region's growth prospects, through

32 Inputs can be also attracted from other regions, especially in the times of growing importance of intangible assets and remote working. 
the transformation of available or creating new activities/domains, preferably with the intensive use R\&D.

Since exports may be treated as a platform for international competitiveness (Krammer, 2017), that gives an opportunity of verifying regional comparative advantages (at international level) and knowing that exports per se provide a significant development chance, thus regional programs could promote the expansion of exportled activity in particular domains (i.e. high-tech or in line with regional SS).

However, Iacobucci and Guzzini (2016) point out that the analysis of strategic documents within the area of smart specialisations brings insufficient inter-regional connections between the selected domains. Furthermore, Radosevic and Ciampi Stancova (2018) imply that trans-regional cooperation, including foreign trade, is a neglected aspect of SS operation, which offers many opportunities. One of the reasons responsible for the situation might be poor understanding or insufficient knowledge on the international competitiveness of local/regional activities by the authorities (Hassink and Gong, 2019).

\subsection{The role of smart specialisation-related exports in regional exports}

Generally, the number of empirical papers evaluating the international aspect of smart specialisations (SS) is very limited, especially within the level of regions. That is why the following analysis presented in the chapter describes the extent to which regional exports conform to SS. The data utilised in the chapter was obtained from the Customs Chamber in Poland and Spanish DataComex (http://datacomex.comercio. es) at 4-digit CN. Owing to the database Eye@RIS, it was possible to grasp SS formulated in particular regions of Poland and Spain. Since SS are characterised by particular NACE rev. 2 activities, there was a need to precisely recode the branch/sector codes to particular product groups in exports at 4-digit CN. However, due to imprecisely formulated SS in agriculture in the Eye@RIS database, one has to bear in mind that estimates for the role of SS in agriculture-related exports may be slightly overestimated. Thus, the authors present the data on exports conforming to SS separately for agricultural and manufacturing goods. Unavailability of data on regional exports in services has restricted the analysis to the first and second sector only. One should remember that in the case of metropolitan regions or border regions, this kind of exports may play an important role in total regions' exports. Two regions of Spain (ES63) Ceuta and (ES64) Melilla, which are city-regions located in Africa were excluded from the analysis, due to the lack of SS priorities.

The approach towards data analysis in the chapter rests on the assumption that regions are analysed without national-wide division. Thus, we present (in most of the cases) regions of two countries jointly, to see if the regional-heterogeneity or national-heterogeneity better depicts the existing differences among regions. Most of the charts and tables present data for the year 2015 only. Since the data till 2005 is also 
available, one may hypothetically verify regional trajectories towards the importance of SS in exports. These are only potential trajectories showing rather the directions to which regional economies direct to, knowing that SS were introduced at the end of the study period.

Coming back to the analysis, the share of exports compliant with regional SS in 2015 was on average higher in Poland (48.1\%) than in Spain (38.3\%). In this respect, well-developed and industrialised regions of Poland (Dolnośląskie, Łódzkie, Wielkopolskie), together with Spanish Galicia and Aragon (mid-ranged in terms of GDP with a significant role of agriculture in the latter) had the highest share (Fig. 12.1). On the other side of the distribution, one may notice Balearic Islands, Catalonia, Region of Murcia (Spain), and Śląskie, Zachodniopomorskie (Poland). The group consisted of highly differentiated regions, indicating the role of the sectoral structure as well as their border/remote location.

In particular regions, like Extremadura, Valencian Community (Spain) and Podlaskie, Lubelskie (Poland), the contribution of agricultural products in exports compliant with SS was significant and exceeded 15\% in all of the above-mentioned cases. Yet, the highest was in Podlaskie (ca. 26\%). The contributions were representing the agriculturally-based type of the economy, in which the first sector played an important role.

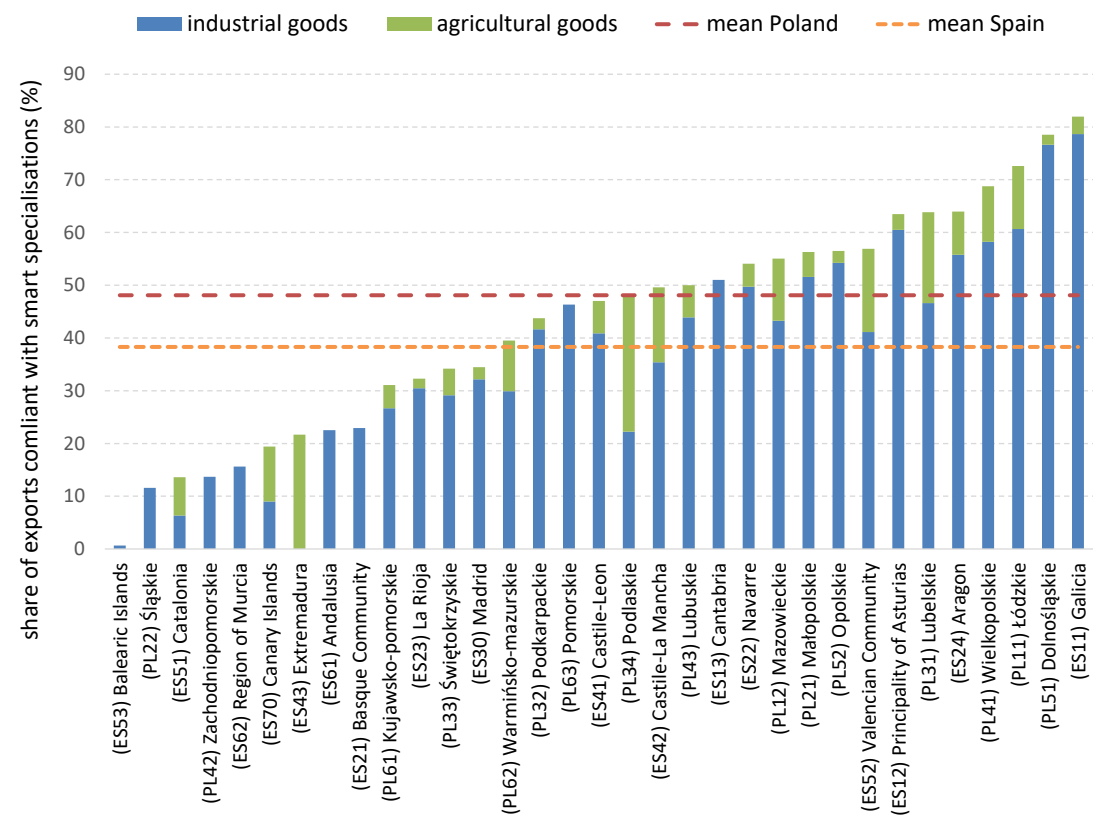

Figure 12.1: Share of exports compliant with regional smart specialisations in 2015 in total exports (\%)

Source: own elaboration. Notes: (ES63) Ceuta and (ES64) Melilla were excluded from the analysis. 
To reveal the importance of SS-related exports in relative terms, we calculate modified location quotient, in which regional shares of SS-compliant exports are related to national shares thereof. Thus, the distinction between regions with a relatively low and high share of exports in line with SS is based on the value of the LQ index (Table 12.1). Lower mean share of SS-compliant exports in regions of Spain has probably affected the final results, as regions of this country dominate among regions having the highest values of the index (above 1.3). Only three Polish regions - Dolnośląskie, Eódzkie, Wielkopolskie anticipated higher than 1.3 values of the location quotient.

As far as hypothetical changes of the LQ index are concerned, the highest was observed in the case of Canary Islands (-0.871), Podkarpackie (0.373) and Castile-La Mancha (0.331). In the first case, they might be the result of relatively small economy of the Canary Islands and prior high importance of agriculture, to which a few new big firms starting their operation might affect the results significantly. In the case of Podkarpackie, it was due to almost twice as high export share of manufacturing products in line with SS, at least to some extent thanks to the expanding aviation sector. Castile-La Mancha contrary to the previous cases, anticipated an increase in the role of agricultural (4.0 pp.) and manufacturing (4.6 pp.) products as well. Thus it generated a high increase in total SS-related exports contribution.

Another dimension diversifying regional export characteristics is product concentration. Since regions have different compositions of sectors and their importance for the whole regional economy, we have decided to present values of the export product analysis divided into those (i) compliant with SS and (ii) non-SS compliant with the use of HHI (Fig. 12.2).

The resulting image clearly differentiates variation among the two, indicating higher in the case of SS-related exports. In regions of Pomorskie, Podkarpackie (Poland), and the Balearic Islands, Castile-Leon, Navarre, Aragon (Spain) the role of a few products was key in total SS-related exports. These were either highly specialised manufacturing regions or small economies to which operation of particular branches/ firms was crucial. Contrary to them, mostly well-developed regions of Poland (with the exception of Lubelskie and Opolskie) had the lowest product concentration of SScompliant exports (see first 8 regions on Fig. 12.2), signalling high differentiation of exporting products falling into SS.

Different contribution of particular products in regions' exports constitutes for their specific regional specialisation, also in the case of products in line with regional SS. Krugman specialisation index is a fairly frequently used metric to reveal crossregional differences in the sectoral composition with a reference area. In the study, it was applied at 4-digit CN for regions' exports to reveal the extent to which regions' composition of product groups is falling into the national-wide volume of exports or the opposite (Fig. 12.3). 


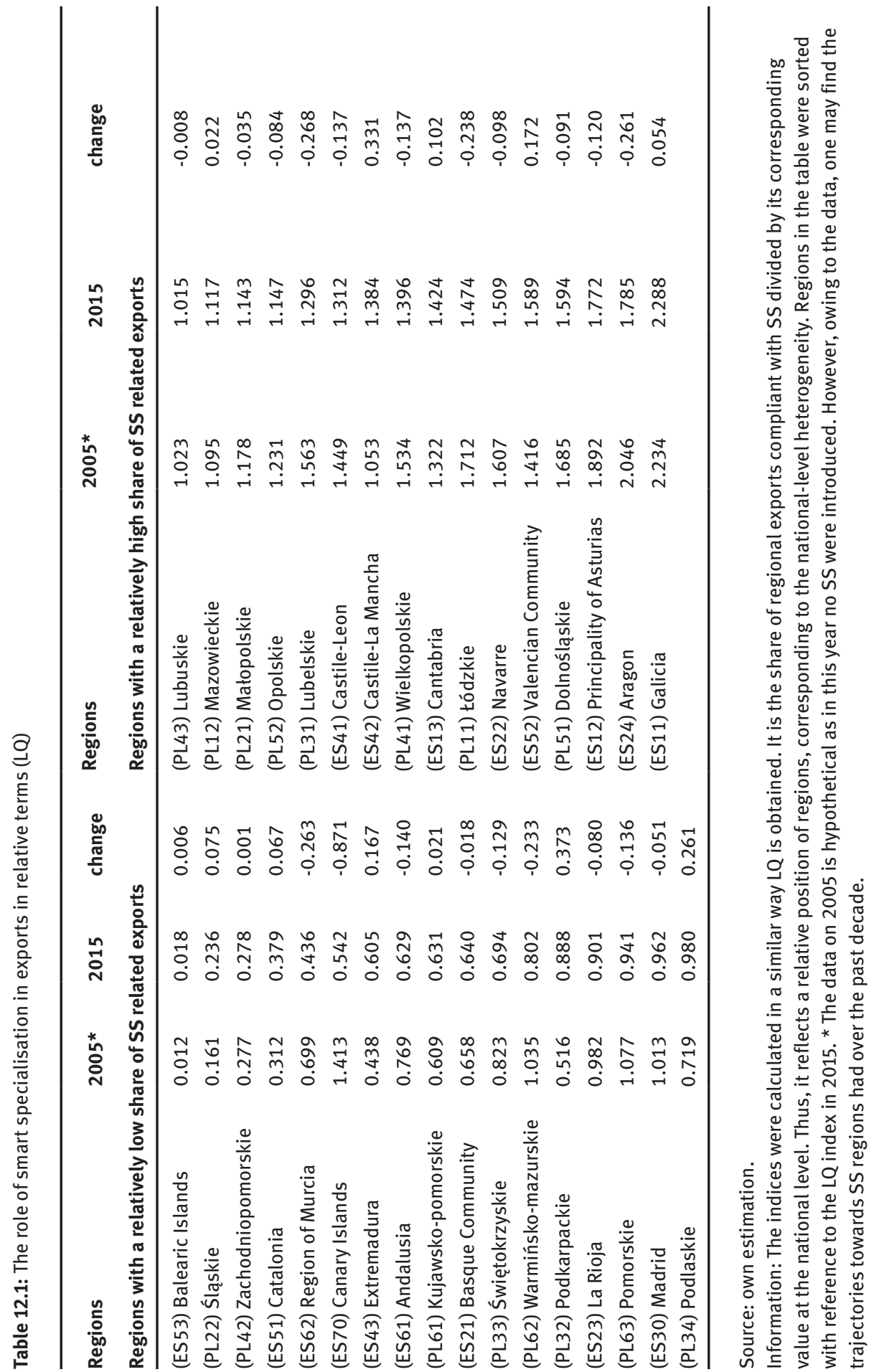




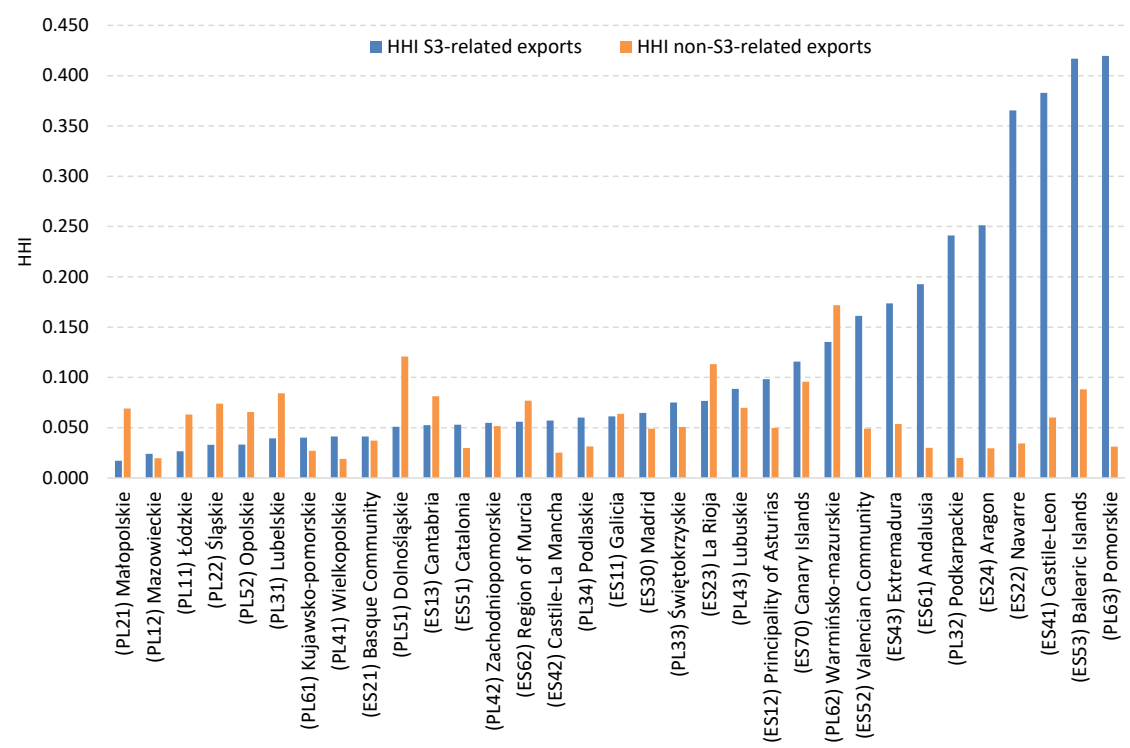

Figure 12.2: Product concentration of SS-related exports vs non-SS-related exports in regions of Spain and Poland in 2015

Source: own elaboration. Notes: Regions were sorted within their HHI SS-related exports.

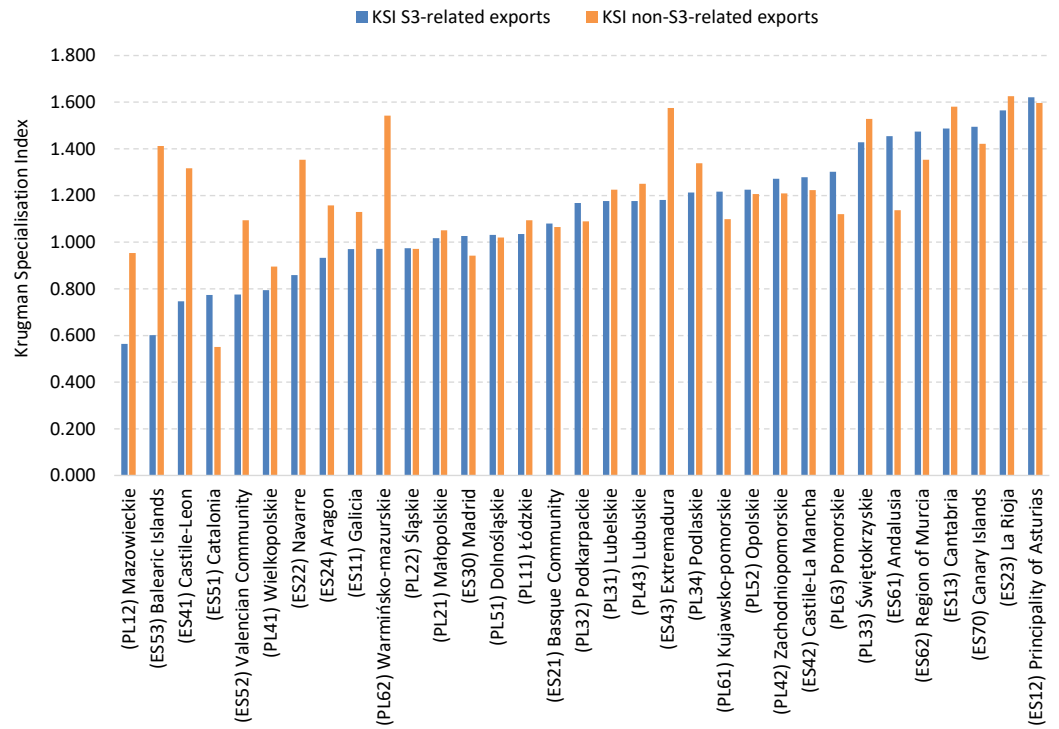

Figure 12.3: Regional specialisation (Krugman Specialisation Index - KSI) of SS-related exports vS non-SS-related exports in regions of Spain and Poland in 2015

Source: own estimates. Notes: Higher values of KSI indicates a higher level of dissimilarity with the total national export structure. 
Due to the fact that the role of SS is a concern in this chapter, the index was calculated for exports (i) falling into SS and (ii) not conforming to the above, separately. Obviously, bigger regions in terms of their contribution to total (national) exports matter more, given their volume of exports; thus they simultaneously are more similar to the reference area, which is national exports.

The highest dissimilarities for SS-related exports were obtained for mainly Spanish regions Principality of Asturias, La Rioja, Canary Islands, Cantabria, Region of Murcia. On the contrary, the lowest were observed in Mazowieckie, Wielkopolskie (Poland), Balearic Islands, Castile-Leon, Catalonia, Valencian Community (Spain).

Since the share of high-tech products in exports may to some extent measure the competitiveness of regional economies, that is why another dimension of the study attempts to verify the extent to which high-tech exports falling into SS matters for total regional exports, compliant with SS. It was not an issue for a few regions of Spain (Basque Community, Extremadura, Catalonia, Balearic Islands, Canary Islands) and one in Poland (Warmińsko-mazurskie) as their share equalled null (Fig. 12.4). These were mostly small and underdeveloped economies (with the exception of Catalonia) and periphery located. On average in 2015, regions of Poland had a higher mean level of high-tech products falling into SS (8.8\%), compared to its Spanish counterparts (4.9).

The highest high-tech products' share in total SS-related exports was observed in Podkarpackie, Śląskie (Poland) and Madrid, Andalusia (Spain). To some extent, the results indicated the importance of aviation valley in Podkarpackie, tech-hub in Madrid, Technological Park in Andalusia, Technological Park in Gliwice (Śląskie).

The results clearly show that only a fraction of regions can build their competitive advantages on the development of high-tech industries since, in most of the regions, the high-tech contribution to SS-related exports is negligible. These could be a result of insufficient attention put to high-tech industries in SS-priorities or their absence/ incidental appearance in regional economies. Regions having a high contribution in this respect anticipated a lower share of high-tech products in total exports, signalling the pro technological orientation of SS in these regions. Albeit, in general terms not all of these regions, had a relatively high share of high-tech products in exports. The case of Śląskie (5.9\%) with below than average contribution of high-tech products in total exports proves that certain regions may build their advantages with intense use of technological-related branches. In light of this, many regions do not attempt to utilize their capabilities, even though they possess an above-average contribution of high-tech products in exports.

Detailed data on exports also enables us to verify the extent to which products created in regions can face international competition. Following Radosevic and Ciampi Stancova (2018), we treat foreign trade as a platform for verification of international competitiveness. To reveal the level of regional competitiveness, a Balasatype revealed competitiveness index (RCA) is calculated, with a reference area of EU, which enables cross-regional comparisons without a distinction of a country of origin. 


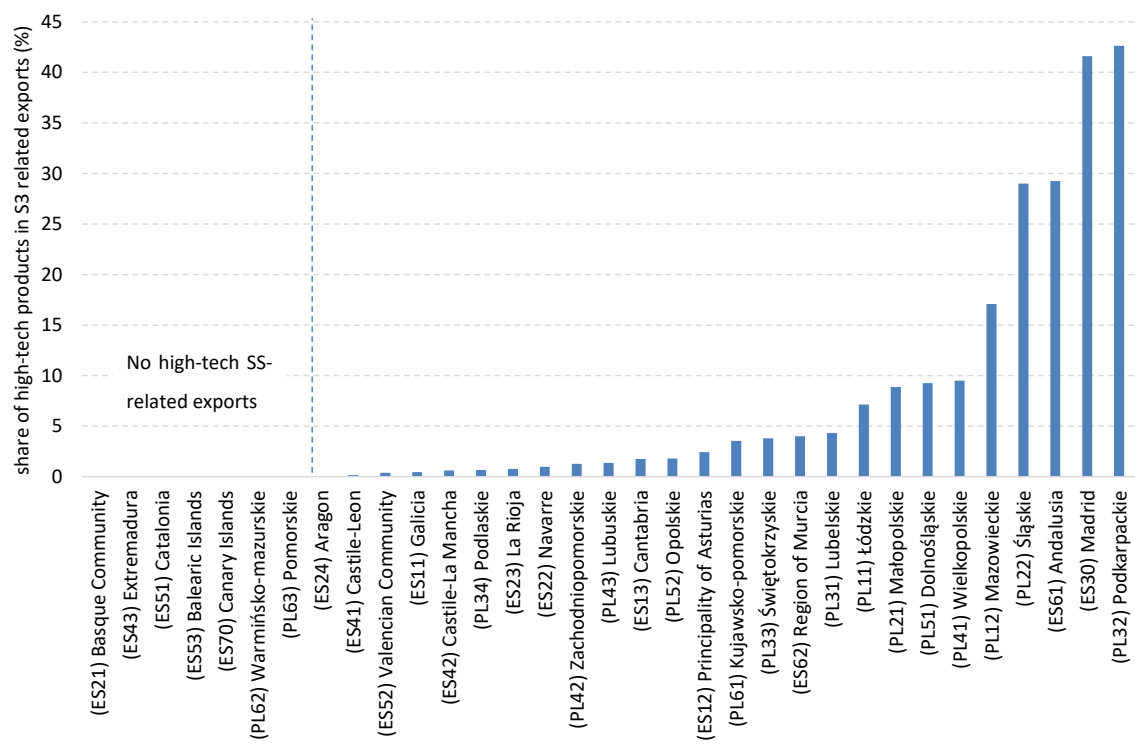

Figure 12.4: Share of high-tech products in SS-related exports in 2015

Source: own estimation.

Since particular product groups have a different contribution to regional exports, the authors decided to utilize the weighted version of RCA of the index. It corrects the possible spikes for RCA in product groups with a small export share. The calculation was carried out for 4-digit CN product groups (ca. 1,300 product groups in total).

The results show the number of product groups in exports (total), as well as the above-number for product groups having WRCA $>2$, WRCA $>5$, respectively (Table 12.2). It represents thus the number of product groups having its share in regional exports two or five times higher than on average in the whole EU. Additionally, information on the number of product groups falling into SS and having WRCA $>2$ or WRCA $>5$ is presented. Finally, by relating the number of products groups in SS-related exports to the total number of products in exports having a high weighted revealed comparative advantage, we try to show the extent to which regional SS (on the basis of export data) fit into the existing comparative advantages in exports at the European level.

The analysed regions differ substantially in terms of the number of products exported, which correlates well with the size of the economies, as well as their level of competitiveness. The highest number of product groups with WRCA $>2$ was a domain of Galicia, Castile-La Mancha (Spain) and Łódzkie, Dolnośląskie, Małopolskie, Wielkopolskie, Mazowieckie (Poland). Yet, these were mostly Polish regions that anticipated the highest share of SS-related product groups with RCA $>2$ in exports, together with Spanish Galicia. A similar situation occurred when dealing with WRCA $>5$.

Particularly interesting is the issue of regions having the lowest share of SSrelated products in exports with WRCA $>2$ like the Balearic Islands, Andalusia (Spain) 
and Zachodniopomorskie (Poland). The regions accrued in their SS less than $10 \%$ of their product groups in exports with high competitiveness. These were mainly tourist regions, with high importance of services in their economies, which due to the type of data provided in the chapter (export of manufacturing and agricultural products) are excluded from the analysis. Thus, in the case of regions where services play a dominant role, the obtained results might be underestimated in terms of showing the real impact of SS. Similarly, mostly manufacturing regions may encounter higher values of the index.

Knowing the above limitations, we try to answer the question in which country on average the SS fit to a higher extent into the existing comparative advantages in product-related exports. In this respect, we address the correlation between the no. of product groups with WRCA $>2$ in exports and corresponding no. of product groups (also with WRCA > 2) in exports compliant with SS. In theory, the higher the match between the two, the higher the $\mathrm{R}^{2}$ representing the goodness of the fit. Scatter plots depicting the existing relations between the variables of interest are presented in figure (Fig. 12.5).
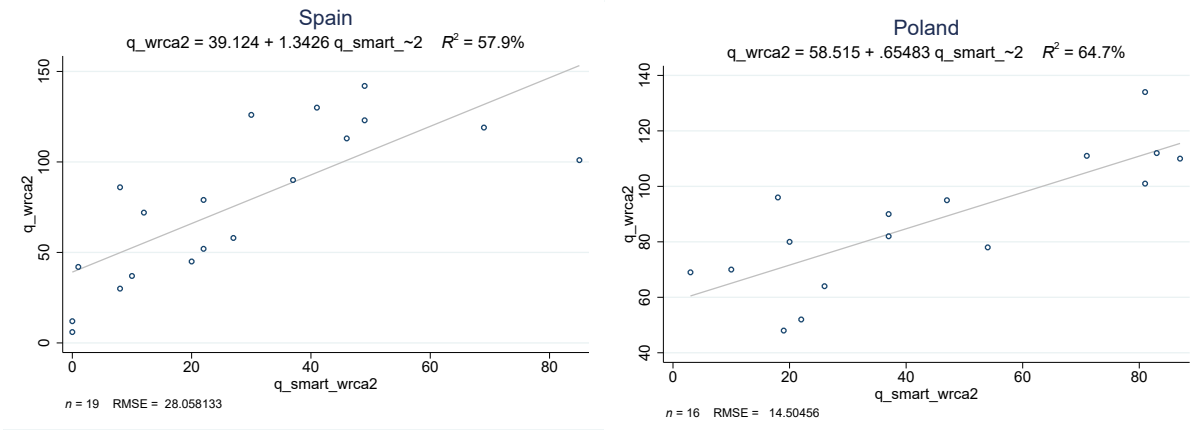

Figure 12.5: Correlation between the no. of product groups with WRCA $>2$ in exports and corresponding no. of product groups (also with WRCA $>2$ ) in exports compliant with SS

Source: own estimates.

On average, Polish regions had a higher fit (64.7\%) in comparison to Spanish ones (57.9\%), which signalled their higher rootedness in endogenous exporting regional potential. Once one removes two Spanish regions Ceuta and Melilla (not having SS) $\mathrm{R}^{2}$ for Spain drops to 49.1. Obviously, the results should be treated with caution, as they do not incorporate exports of services. However, they directly show more product and export-oriented approach towards establishment of SS in Polish regions.

Finally, changes in the importance of SS in exports were calculated. Since SS were introduced at the end of the available time span, the indices presented below may be treated only as hypothetic due to data constraints. We show them only to present 
Table 12.2: No. of product groups in 2015 with high WRCA in total exports and compliant with smart specialisations

\begin{tabular}{|c|c|c|c|c|c|c|c|}
\hline Region & $\begin{array}{l}\text { No. of } \\
\text { product } \\
\text { groups }\end{array}$ & $\begin{array}{l}\begin{array}{l}\text { Total } \\
\text { exports }\end{array} \\
\text { WRCA > }\end{array}$ & $\begin{array}{l}\text { SS } \\
\text { exports }\end{array}$ & SS (\%) & $\begin{array}{l}\text { Total } \\
\text { exports }\end{array}$ & $\begin{array}{l}\text { SS } \\
\text { exports }\end{array}$ & SS (\%) \\
\hline (ES11) Galicia & 1045 & 101 & 85 & 84.2 & 49 & 41 & 83.7 \\
\hline (PL11) tódzkie & 968 & 101 & 81 & 80.2 & 36 & 29 & 80.6 \\
\hline (PL51) Dolnośląskie & 987 & 110 & 87 & 79.1 & 42 & 34 & 81.0 \\
\hline (PL21) Małopolskie & 1017 & 112 & 83 & 74.1 & 57 & 42 & 73.7 \\
\hline (PL31) Lubelskie & 910 & 78 & 54 & 69.2 & 35 & 30 & 85.7 \\
\hline (PL41) Wielkopolskie & 1051 & 111 & 71 & 64.0 & 54 & 35 & 64.8 \\
\hline (PL12) Mazowieckie & 1132 & 134 & 81 & 60.4 & 48 & 31 & 64.6 \\
\hline (ES42) Castile-La Mancha & 957 & 119 & 69 & 58.0 & 43 & 20 & 46.5 \\
\hline (PL52) Opolskie & 839 & 95 & 47 & 49.5 & 42 & 25 & 59.5 \\
\hline (ES12) Principality of Asturias & 783 & 58 & 27 & 46.6 & 29 & 12 & 41.4 \\
\hline (PL43) Lubuskie & 824 & 82 & 37 & 45.1 & 44 & 23 & 52.3 \\
\hline (ES13) Cantabria & 653 & 45 & 20 & 44.4 & 27 & 14 & 51.9 \\
\hline (PL33) Świętokrzyskie & 636 & 52 & 22 & 42.3 & 29 & 11 & 37.9 \\
\hline (ES23) La Rioja & 679 & 52 & 22 & 42.3 & 26 & 12 & 46.2 \\
\hline (PL61) Kujawsko-pomorskie & 857 & 90 & 37 & 41.1 & 44 & 16 & 36.4 \\
\hline (ES41) Castile-Leon & 966 & 90 & 37 & 41.1 & 34 & 8 & 23.5 \\
\hline (ES24) Aragon & 963 & 113 & 46 & 40.7 & 35 & 13 & 37.1 \\
\hline (PL34) Podlaskie & 815 & 64 & 26 & 40.6 & 31 & 14 & 45.2 \\
\hline (ES52) Valencian Community & 1152 & 123 & 49 & 39.8 & 52 & 22 & 42.3 \\
\hline (PL62) Warmińsko-mazurskie & 763 & 48 & 19 & 39.6 & 26 & 9 & 34.6 \\
\hline (ES51) Catalonia & 1205 & 142 & 49 & 34.5 & 34 & 15 & 44.1 \\
\hline (ES30) Madrid & 1168 & 130 & 41 & 31.5 & 39 & 17 & 43.6 \\
\hline (ES22) Navarre & 822 & 79 & 22 & 27.8 & 31 & 7 & 22.6 \\
\hline (ES70) Canary Islands & 797 & 37 & 10 & 27.0 & 22 & 7 & 31.8 \\
\hline (ES43) Extremadura & 733 & 30 & 8 & 26.7 & 15 & 6 & 40.0 \\
\hline (PL32) Podkarpackie & 900 & 80 & 20 & 25.0 & 26 & 3 & 11.5 \\
\hline (ES21) Basque Community & 1079 & 126 & 30 & 23.8 & 52 & 16 & 30.8 \\
\hline (PL22) Śląskie & 1070 & 96 & 18 & 18.8 & 43 & 9 & 20.9 \\
\hline (ES62) Region of Murcia & 916 & 72 & 12 & 16.7 & 36 & 6 & 16.7 \\
\hline (PL63) Pomorskie & 909 & 70 & 10 & 14.3 & 33 & 7 & 21.2 \\
\hline (ES61) Andalusia & 1119 & 86 & 8 & 9.3 & 51 & 4 & 7.8 \\
\hline (PL42) Zachodniopomorskie & 923 & 69 & 3 & 4.3 & 32 & 0 & 0.0 \\
\hline (ES53) Balearic Islands & 653 & 42 & 1 & 2.4 & 26 & 0 & 0.0 \\
\hline
\end{tabular}

Source: own estimation.

Note: data were sorted by the $5^{\text {th }}$ column. 
the possible trajectories regional economies direct to as regards the share of exports compliant with SS.

Surprisingly, the mean share of SS-related exports followed two different paths in Poland and Spain (Fig. 12.6). While it increased in Poland from ca. 45.9\% in 2005 to $48.1 \%$ in 2015, in Spain it followed a different trend. Mean share of exports compliant with SS decreased in Spain from $43.3 \%$ to $38.3 \%$ within the same period. The results seem to be unforeseeable as they present different approaches to changes in the role of SS. Yet, one has to keep in mind that the results of the inquiry, presented in that chapter, cover only agricultural and manufacturing products; thus the apparent decreased trend in Spanish regions may stem from their structural changes owing to shifts from the role of the first and second sector to the third sector of the economy. These needs obviously further research.

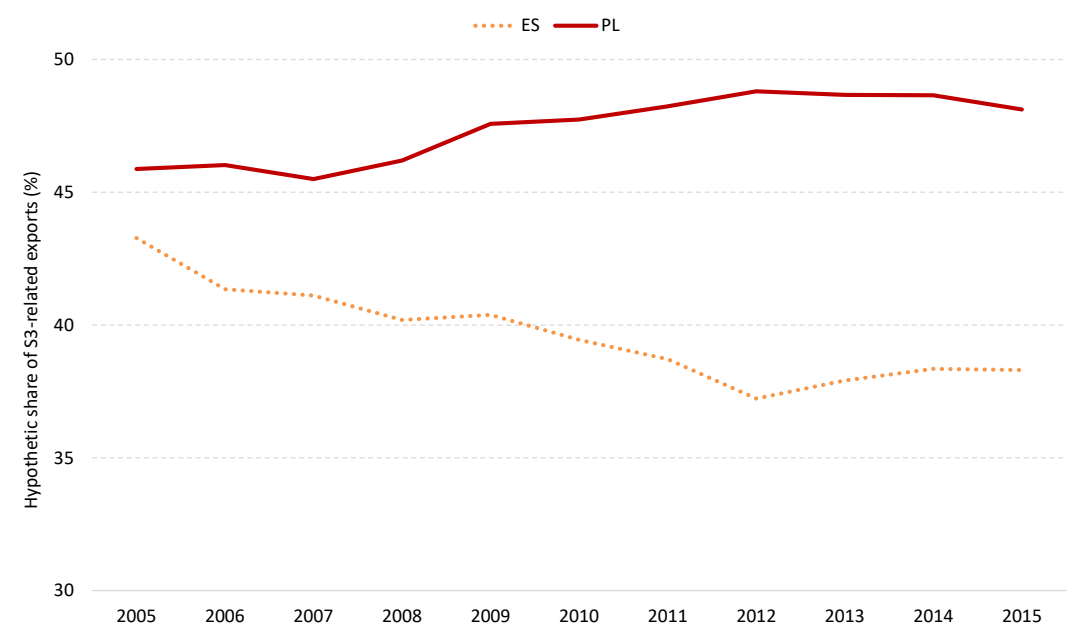

Figure 12.6: Hypothetic mean share of SS-related exports in regions of Spain and Poland between 2005 and 2015

Source: own elaboration.

\subsection{Conclusions}

Most of the differences between Polish and Spanish regions in terms of the role SS play in exports stem from cross-regional heterogeneity; however, few characteristics seem to be more country-specific. Generally, the mean contribution of exports in line with SS was on average higher in the case of Polish regions as compared to their Spanish counterparts, yet it is only a part of the bigger picture, due to data constraints (lack of information on exports in services). Thus, it is difficult to precisely answer the question to what extent regions utilize their export potential in terms of formulated SS. 
In fact, the available data shows, however, that many regions could do better in exploiting their existing comparative advantages in exports as their number of products with revealed comparative advantages (when EU market is taken as a reference) greatly surpass the number of product groups with RCA in SS-related exports. The findings also direct to the need of higher attention put to the use of exporting data or RCAs in SS.

Since foreign trade may be treated as a platform verifying international competitiveness, local/regional authorities with the knowledge of region's RCAs, as well as other region-specific characteristics (incl. ability to generate $R \& D$ in particular activities), may increase their chances to fit into domains/industries that have strong revealed competitive advantages in the region, that could have enough critical mass to initiate positive structural shifts (i.e. with the collaboration of R\&D). To date, it seems to be a neglected aspect of SS strategy as regional strategic documents and operational programmes predominantly do not incorporate this type of international activity in their priorities.

Since foreign trade is a true validator or international competitiveness, which verifies comparative advantages regions have, there is a need of higher attention put to the international aspect of competitiveness in the process of SS' formulation. This product-based approach offers a high resolution of the data needed to depict specialisations, thus gives the possibility of a precise declaration of particular SS. Secondly, it enables fairy easy post-evaluation of the already set priorities, given the availability of regional trade data in selected countries. It can also provide evidence-based information on the role of particular industries/activities regions have in terms of their competitiveness as well as to better understand the foundations of the regional competitiveness. 
